\title{
The Great Recession Index: A Place-based Indicator for Countries, States, and Metropolitan Areas
}

\author{
Michael Wallace ${ }^{1}$ D $\cdot$ Angran $\mathrm{Li}^{2} \cdot{\text { Allen } \mathrm{Hyde}^{3}}^{3}$
}

Accepted: 8 September 2021 / Published online: 5 October 2021

(C) The Author(s), under exclusive licence to Springer Nature B.V. 2021

\begin{abstract}
The Great Recession (GR) of 2007-2009 marked the most devastating economic downturn since the Great Depression of the 1930s, and its consequences dramatically changed almost every aspect of social life. This research introduces the Great Recession Index (GRI), a place-based composite measure that captures the multidimensional nature of the GR. The GRI can be used to examine macro-level outcomes and is especially well-suited for examining the spatial variation and longterm effects of the GR. The GRI is adaptable to a variety of geospatial units of analysis, and in this article, we develop measures for countries, U.S. states, and U.S. metropolitan areas. Then, using the state-based GRI, we provide a research application to demonstrate the utility of the GRI for explaining state-level income inequality in the post-Recession period. The results show that the initial shock of the GR decreased the income share of upper-class households, but the aftershock of the Recession increased their income share, resulting in increased income inequality in the U.S. since the Recession. This paper concludes by considering the feasibility of using similar measures for evaluating the effects of catastrophic events such as wars, civil unrest, climate change, natural disasters, or pestilence on societal outcomes.
\end{abstract}

Keywords Great Recession · Great Recession Index · Longitudinal and spatial measures of economic downturns $\cdot$ Income inequality

Michael Wallace

michael.wallace@uconn.edu

Angran Li

angranli19@gmail.com

Allen Hyde

allen.hyde@hsoc.gatech.edu

1 Department of Sociology, University of Connecticut, 344 Mansfield Rd, Storrs, CT 06269-2068, USA

2 Department of Sociology, Zhejiang University, Hangzhou, China

3 School of History and Sociology, Georgia Institute of Technology, 221 Bobby Dodd Way, Atlanta, GA 30308-0025, USA 


\section{Introduction}

The Great Recession of 2007-2009 marked the greatest economic collapse since the Great Depression of the 1930s, and its ramifications quickly reverberated through a tightly interlocked global economy. A spate of scholarly collections rushed to document the social, economic, and political fallout of the Recession (Reardon, 2009; Grusky et al., 2011; Mishel et al., 2012; Danziger, 2013; Kahler \& Lake, 2013; Seefeldt \& Graham, 2013; Rosenfeld, 2014; Kalleberg \& von Wachter, 2017). The Recession's influence was farreaching and touched almost every facet of social life including education (Fogg \& Harrington, 2011); the labor market (Daly \& Marks, 2014), work (Havins, 2014) and retirement (Butrica et al., 2010); family (Gillespie, 2014), fertility (Schneider, 2015) and child welfare (Rouse \& Ross, 2018); poverty (Sherman, 2013) and the social safety net (Moffitt, 2013); health and well-being (Burgard \& Kalousova, 2015), mental health (Cagney et al., 2014), and suicide (Houle \& Light, 2014); government fiscal policy (Tcherneva, 2012), policy preferences (Margalit, 2013) and public opinion (Brooks \& Manza, 2013); migration (Johnson et al., 2017) and immigration (Villarreal, 2014); domestic violence (Schneider et al., 2016) and crime (Pontell \& Geis, 2014); popular culture (Schuyler, 2015); and happiness (O'Connor, 2017).

This copious body of research has contributed greatly to our understanding of the impact of the Great Recession (hereafter, "GR"). However, despite its breadth, it has several limitations.

First, most research fails to account for the multidimensional nature of the GR, that is, the confluence of four economic crises-economic decline, employment loss, the housing crash, and the financial crisis - of which it was comprised. Second, it skews heavily toward micro-level analyses that can be readily investigated using individual-level datasets and eschews rigorous investigation of important macro-level outcomes. Third, there is not much consideration for how spatial variations in the timing and severity of the GR lead to different effects in diverse geographical contexts. Fourth, extant research on the GR focuses almost exclusively on short-term impacts and has largely ignored long-term aftershocks of the Recession. This is despite the emphasis in early research on the potentially transformative effects of the GR on the whole of American society (Peck, 2010). These factors combined to produce a short burst of publications that peaked about five years after the Recession, and a slow fizzling out in GR research in subsequent years. ${ }^{1}$

There is still much to learned about the ongoing after-effects of the GR, particularly those that are not easily ascertained from a focus on short time horizons. Thus, a challenge for social researchers is to devise a method to overcome these limitations. In this paper, we develop the Great Recession Index (hereafter, GRI), so-named because it is a composite measure that captures the multidimensional nature of the GR as well as its differential severity across time and space. Moreover, the GRI can be used to probe macro-level outcomes and is especially well-suited for examining the long-term effects of the GR. Finally, the GRI is adaptable to a variety of geospatial units of analysis where the necessary data are available. In this paper, we describe procedures for developing the GRI for countries, U.S. states, and U.S. metropolitan areas. Then, using the state-based GRI, we present a

\footnotetext{
1 To ascertain trends in GR research, we used JSTOR to search articles in all disciplines that had the phrase "Great Recession" in the title for the years 2009-2020. The number of articles found was as follows: $2009=5,2020=17,2011=26,2012=30,2013=45,2014=42,2015=24,2016=21,2017=18$, $2018=10,2019=4,2020=1$.
} 


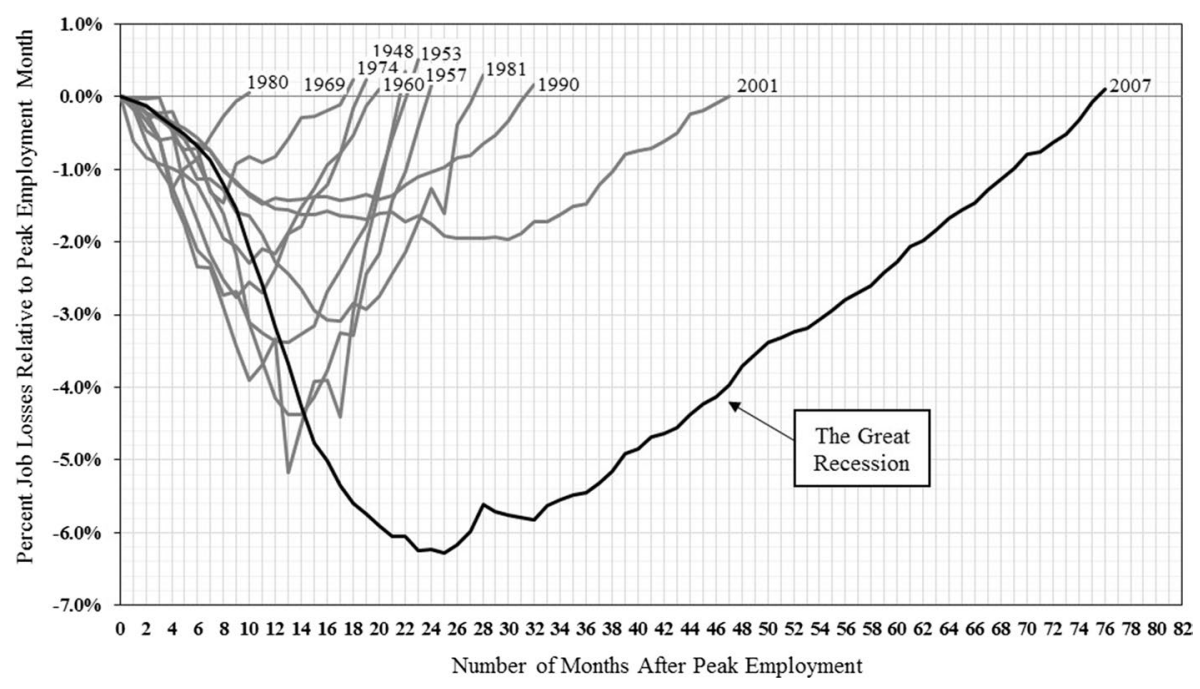

Fig. 1 Percent job losses in post-WWII recessions

research application using the state-based data to demonstrate the utility of the GRI for explaining income inequality in the post-Recession period. We conclude by considering the broader implications of the GRI and similar measures for evaluating the effects of catastrophic events on societal outcomes.

\section{Conceptualizing the Great Recession Index}

In the U.S., the Great Recession officially lasted 19 months from December 2007 to June 2009, but economic repercussions of the Recession lasted much longer, as did the social, psychological, and emotional impact. Additionally, the GR did not play out evenly within the United States or among other countries in the world. It started earlier, reached greater depths, and was of longer duration in some places than others. Moreover, the GR represented not a single dimension of economic collapse but rather a confluence of multiple interrelated economic crises, each of them following their own rhythm of decline and recovery.

Figure 1 portrays the scale of the GR in the United States compared to all other postWorld War II recessions, based on a single indicator-employment loss. The figure shows that the severity and duration of employment loss in the GR far exceeded all other recessions in the postwar era. At its nadir, the GR cost about 8.8 million U.S. jobs or $6.4 \%$ of the jobs at the pre-Recession peak, and it took about 76 months to recoup those losses. Even as employment grew beyond that point, the recovery was sluggish and lagged far behind where employment would have been had the Recession never occurred. In fact, national employment did not catch up with its demographically-adjusted, pre-Recession level until 10 years after the pre-Recession peak in November 2007 (Schanzenbach et al., 2016). Also, 10 years after the official end of the Recession in June 2009, the share of the population employed had not yet recovered to pre-Recession levels (McCorkell \& Hinkley, 2019). The post-Recession labor market has been characterized by reduced job quality, stagnating wages for working- and middle-class earners, and rising income inequality. And its 
impacts have been unevenly distributed by gender, race and ethnicity, education, and age (Schanzenbach et al., 2016).

Figure 1 gives insight as to how to construct an index to measure the impact of the GR. By comparing levels of employment, in this case, at specified points during the trough of the Recession to pre-Recession peak-level employment, we can derive a measure of the severity of the Recession. From the raw data used to construct Fig. 1, we know that peak employment occurred in January 2008 at 138,430,000 employees. This can be compared to employment levels in January of each of the following five years: $2009=134,053,000$; $2010=129,801,000 ; \quad 2011=130,882,000 ; \quad 2012=133,288,000 ; \quad 2013=135,283,000$. If we express each of these as a proportion of peak employment, we get: $2009=0.968$; $2010=0.938 ; 2011=0.945 ; 2012=0.963 ; 2013=0.977$. Inverting these proportions expresses the severity of each year's employment loss relative to peak employment: $2009=1.033 ; 2010=1.066 ; 2011=1.058 ; 2012=1.039 ; 2013=1.023$. Then, taking the mean of these five inverted values $(=1.044)$ expresses the severity of employment loss over the five-year period following peak employment.

We should note one important caveat in this example. Whereas the national employment data on which Fig. 1 is based are available on a monthly basis, many indicators available to researchers for countries, states, or metropolitan areas are only available on an annual basis. Moreover, most longitudinal analyses in which researchers would use the GRI will employ annual data. Thus, the GRI is constructed using publicly-available, annual data. ${ }^{2}$ In the ensuing discussion, we will develop this procedure more fully. In this discussion, we identify five aspects that are critical in this process: dimensionality, timing, duration, severity, and synchronicity. We discuss each of these in turn.

\subsection{Dimensionality}

The question of dimensionality is: How many dimensions of economic crisis comprise the $G R$ ? While researchers often assume that the Recession had a single dimension that can be captured with a measure such as the unemployment rate, we identify four separate but interrelated economic crises, each constituting a unique dimension of the GR.

The first dimension, discussed above, is employment loss, which captures the amount of employment that has been lost relative to pre-Recession peak levels of employment over a specified period of time.

The second dimension of the GR is economic decline, which is based on declining inflation-adjusted Gross Domestic Product (GDP), the primary criterion used by the National Bureau of Economic Research (2021) to define the beginning and end of recessions. At the national level, economic decline reached its nadir in the third quarter of 2008 with a $7.0 \%$ loss in economic output over the previous quarter. A full turnaround was not achieved until a year later when the economy grew by $4.9 \%$ (FRED, 2020). We define economic decline

\footnotetext{
2 The GRI is distinguished from the "US Business Cycle Expansions and Contractions" (National Bureau of Economic Research, 2021) and other similar measures in several respects. First, it is tailored to measure the precise dimensions that were most prominent in the Great Recession. Second, it measures not simply whether the economy was in recession of expansion, but the magnitude of decline or growth over a period of time. Third, it is not merely a national-level measure for a single country (the U.S.), but rather can be developed for sub-national geographical units like states or metropolitan areas, or for other countries besides the U.S.
} 
as the level of inflation-adjusted GDP per capita relative to pre-Recession peak levels of GDP per capita over a specified duration of time.

The third dimension of the GR is the housing crash, variously known as the subprime mortgage crisis or the home foreclosure crisis. Fligstein and Goldstein (2011) identify the housing crisis as the root cause of the Great Recession. This crisis was precipitated by a bubble in housing prices in the early 2000s caused by speculative investing in subprime mortgages and the deregulation of the financial industry. On average, national housing prices in the U.S. increased by $67.5 \%$ between early 2000 and early 2007 , then declined by $19.6 \%$ by early 2011 (FRED, 2020). Millions of homeowners lost their homes, and the crash contributed significantly to the collapse of the labor market. The housing crash is measured by the housing price index (HPI) relative to pre-Recession peak levels of the HPI over a specified duration of time.

The fourth dimension of the GR is the financial crisis, which stemmed from a toxic mix of deregulation of the financial industry, the origination of complex financial instruments, the "too-big-to-fail" syndrome, and the expansion of risky financial practices like leveraging (Wright \& Rogers, 2015: 200-209). These processes vastly expanded risky, profitseeking opportunities for major financial institutions while making homeowners, small investors, and consumers bear most of the risk. As a result, the financial industry suffered severe losses in their financial assets, but they recovered relatively quickly compared to those who bore the brunt of the crisis. The financial crisis is measured as the level of inflation-adjusted profits (value-added in the country-level analysis) in the financial sector relative to pre-Recession peak levels of profits (value-added) over a specified duration of time.

\subsection{Timing}

The question of timing is: When did the GR begin? Or, more specifically, in light of the discussion of dimensionality, When did each economic crisis comprising the GR begin? The second question presupposes the question of the synchronicity that we address below, but for now we are concerned with identifying the point when a particular economic dimension began to decline. We do so by identifying the pre-Recession peak, which is the highest point in the cycle before a sustained decline began. So, in the example from Fig. 1, employment reached its highest level in January 2008 at 138,430,000, after which it entered a 76-month trough. (We remind the reader of our previous caveat that the data used in constructing the GRI are annual, not monthly.) In some geographical areas less impacted by the Recession, a particular indicator never declined, but its rate of increase slowed. In these cases, the pre-Recession peak was identified as the point in time preceding the largest decrease in the rate of increase. In our analyses using annual data, most pre-Recession peaks occurred in 2006 and 2007, but a few began in 2005 or 2008.

\subsection{Duration}

The question of duration is: How long did each dimension of economic crisis last? Ideally, we would identify the point in time when a particular indicator attained or surpassed its pre-Recession level. In the employment example in Fig. 1, this level was not achieved until April 2014 or 76 months after the pre-Recession peak. Using annual data, we quickly ascertained that it would be impractical to try to measure the exact duration of each cycle. Rather, we opted to reframe the duration question as: What was the status of a particular dimension at a fixed duration of time after the pre-Recession peak? We constructed 
three alternative versions of the GRI using three "duration windows" and leave it to the researcher to choose based on theoretical and empirical considerations. The three windows were created at three-year, four-year, and five-year intervals. Drawing on the example in Fig. 1, based on the January 2008 pre-Recession peak, the three-year window would encompass the period through January 2011; the four-year window, through January 2012; and the five-year window, through January 2013. We note that in many cases, a particular dimension did not eclipse its pre-Recession peak even by the end of the five-year window. Thus, rather than identifying the exact duration of a particular cycle, the windows provide "snapshots" of the status of a cycle after a fixed duration in time.

\subsection{Severity}

The question of severity is: What is the cumulative toll exacted over the duration of each economic crisis? This question can be only crudely addressed with a single snapshot comparing the end of the crisis to the pre-Recession peak. In order to address this issue more precisely, we decided to take multiple snapshots at annual intervals throughout the duration of the crisis. So, using the employment data from Fig. 1, we would construct a five-year measure of severity by indexing the first-, second-, third-, fourth-, and fifth-year values of employment to the pre-Recession peak and taking the mean $(((1.033+1.066+1.058$ $+1.039+1.023) / 5)=1.044)$. In this example, 1.044 expresses the severity of the national employment crisis over the five-year period following the start of the pre-Recession peak. Severity measures for three-year and four-year windows were constructed analogously. Such measures have the advantage of pooling information across the duration of the crisis rather than relying on a single point in time.

\subsection{Synchronicity}

The question of synchronicity is: Is the timing of the four economic crises synchronous or asynchronous? That is, do their pre-Recession peaks occur at the same time or not? Many accounts of the GR suggest that the various crises, though connected, did not occur simultaneously. The housing crisis triggered the financial crisis, which in turn set in motion economic decline and employment loss. This coincides with the empirical evidence in our country-level, state-level, and metropolitan-level data that the crises are generally asynchronous. Indeed, even with the annual data we use, it is far more likely that the pre-Recession peaks of all four crises did not occur in the same year than that they did. Even so, data limitations or other practical concerns may require researchers to impose the restriction that the peaks of the four crises are synchronous.

To accommodate needs of researchers, we constructed two types of GRI measures: fixed-peak, which assumes that the peaks occur simultaneously in a particular year, and floating-peak, which allows the peaks to vary according to the year that they actually occurred. We constructed four sets of fixed-peak GRIs, beginning in either 2005, 2006, 2007, or 2008, each set including three-year, four-year, and five-year variants, for a total of 12 fixed-peak variations of the GRI. We constructed one set of floating-peak GRIs, which includes three-year, four-year, and five-year variants, for a total of three floating-peak variations of the GRI. (Only one set of three is necessary for floating-peak variants because the peaks of each crisis are permitted to vary.) Further details of the construction of different variations of the GRI are provided below. 


\section{Datasets}

Our goal is to create a Great Recession Index that can be utilized by researchers in diverse research contexts to examine the short-term and long-term consequences of the GR on a variety of social outcomes. To this end, we utilize three datasets to facilitate the construction of the GRI at the country, state, and metropolitan levels, all created under the supervision of the first author from publicly available sources. ${ }^{3}$ At the country level, we use the 36_Nations dataset, a longitudinal dataset spanning the years 1960-2020 and comprised of the 36 countries that are full members of the Organisation for Economic Co-operation and Development. At the state level, we use the 50_States dataset, a longitudinal dataset for the 50 U.S. states spanning 1946-2020. At the metropolitan level, we use the Metro_ Micro_2010 dataset, which includes data for 374 metropolitan and 589 micropolitan statistical areas in the U.S. and Puerto Rico identified in 2010. We limit our analysis to the 366 metropolitan areas not located in Puerto Rico.

Table 1 provides data sources and variable construction for each of the four components used to construct the GRI for the country-level, state-level, and metropolitan-level datasets used in this analysis. Importantly, metro-level data on financial sector profits were not available so we substituted state-level profits from the state dataset. To reiterate, all measures used in the construction of the GRI employ publicly-available, annual data.

\section{The Great Recession Index}

To summarize, we seek to create a place-based Great Recession Index that succinctly measures the economic impact of the Great Recession at the country, state, and metropolitan levels. The measure should address the multidimensionality of the Recession by including four intertwined economic crises: employment loss, economic decline, the housing crisis, and the financial crisis. The GRI should also be sensitive to the varying timing, duration, and severity of the Recession in different geographic places. Finally, the GRI should permit researchers to choose between synchronous and asynchronous versions of the index based on their research priorities.

The procedures for constructing the GRI are as follows: For each dimension of the crisis, we identified the pre-Recession peak value as occurring in one of four years-2005, 2006, 2007, or 2008. We allowed for both synchronous and asynchronous variations. Next, we took the average level for each dimension over the next $t$ years ( $t$ refers to the three-, four-, or five-year windows) as a proportion of the peak level for that dimension. We then converted these four proportions to z-scores, re-keyed the z-scores so that higher values indicated more severe effects of the Recession, and averaged the four re-keyed z-scores to create the GRI. This procedure can be expressed mathematically as follows:

$$
G R I_{S, A}=\frac{z_{E}^{R}\left\{\frac{\sum_{t=1}^{3,45} \frac{e_{t}}{E}}{t}\right\}+z_{G}^{R}\left\{\frac{\sum_{t=1}^{3,45} \frac{g_{t}}{G}}{t}\right\}+z_{F}^{R}\left\{\frac{\sum_{t=1}^{3,45} \frac{f_{t}}{F}}{t}\right\}+z_{H}^{R}\left\{\frac{\sum_{t=1}^{3,45} \frac{h_{t}}{H}}{t}\right\}}{4}
$$

where GRI is the Great Recession Index, s,A references the option to use synchronous or asynchronous versions of the index, $t$ is the number of years after the peak year $(3,4$, or 5$)$,

${ }_{3}^{3}$ Details about these data files are available from the authors upon request. 


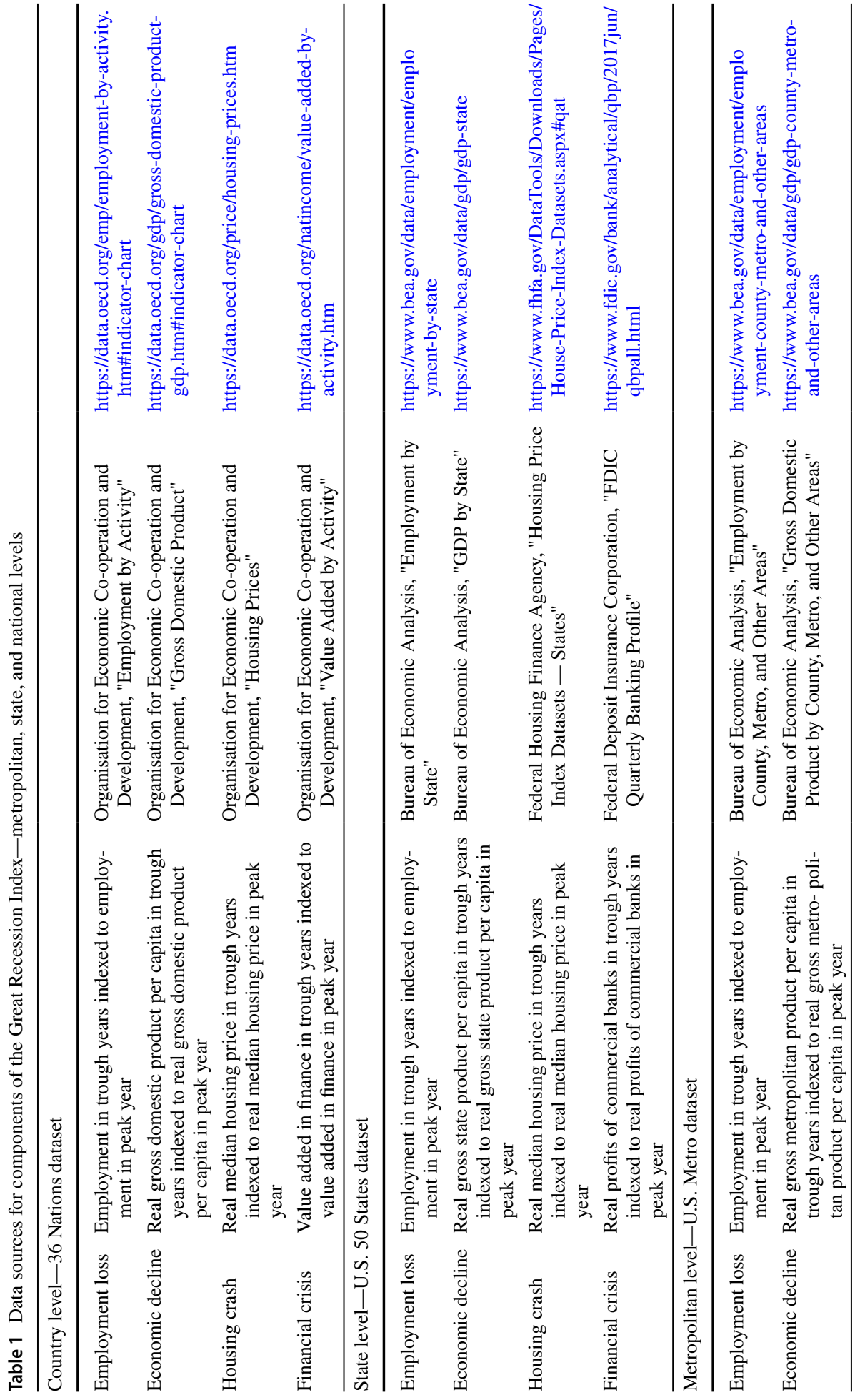




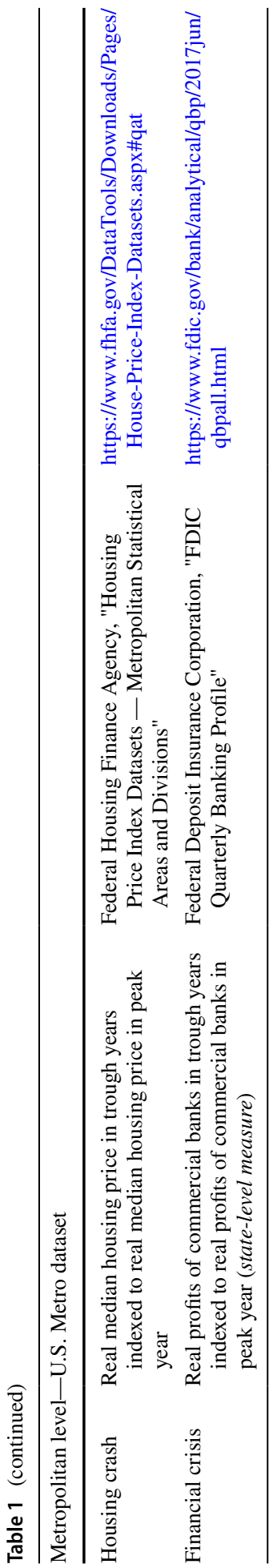


Table 2 Cronbach's alpha for 15 alternative measures of the Great Recession Index

\begin{tabular}{|c|c|c|c|c|c|c|c|}
\hline Variable & Type & Peak year & Duration & Years & Country-level & State-level & Metro-level \\
\hline GRI-1 & Fixed peak & 2005 & 3 years & 2006-2008 & .677 & .652 & .588 \\
\hline GRI-2 & Fixed peak & 2005 & 4 years & 2006-2009 & .620 & .706 & .645 \\
\hline GRI-3 & Fixed peak & 2005 & 5 years & 2006-2010 & .633 & .723 & .685 \\
\hline GRI-4 & Fixed peak & 2006 & 3 years & $2007-2009$ & .553 & .770 & .728 \\
\hline GRI-5 & Fixed peak & 2006 & 4 years & 2007-2010 & .690 & .802 & .756 \\
\hline GRI-6 & Fixed peak & 2006 & 5 years & $2007-2011$ & .763 & .819 & .768 \\
\hline GRI-7 & Fixed peak & 2007 & 3 years & 2008-2010 & .875 & .832 & .764 \\
\hline GRI-8 & Fixed peak & 2007 & 4 years & 2008-2011 & .873 & .845 & .776 \\
\hline GRI-9 & Fixed peak & 2007 & 5 years & 2008-2012 & .861 & .847 & .778 \\
\hline GRI-10 & Fixed peak & 2008 & 3 years & 2009-2011 & .870 & .647 & .605 \\
\hline GRI-11 & Fixed peak & 2008 & 4 years & 2009-2012 & .846 & .671 & .623 \\
\hline GRI-12 & Fixed peak & 2008 & 5 years & 2009-2013 & .836 & .666 & .612 \\
\hline GRI-13 & Floating peak & varies & 3 years & Varies & .883 & .848 & .697 \\
\hline GRI-14 & Floating peak & varies & 4 years & Varies & .886 & .869 & .757 \\
\hline GRI-15 & Floating peak & varies & 5 years & Varies & .881 & .880 & .780 \\
\hline
\end{tabular}

$E$ is peak level of employment, $e_{t}$ is the employment level in year $t, z_{E}^{R}$ is the re-keyed value of the z-score for the employment loss component, $G$ is peak level of GDP per capita, $g_{t}$ is the level of GDP per capita in year $t, z_{G}^{R}$ is the re-keyed value of the z-score for the economic decline component, $F$ is peak level of profits (value added) in the financial sector, $f_{t}$ is the level of profits (value added) in the financial sector in year $t, z_{F}^{R}$ is the re-keyed value of the z-score for the financial crisis component, $H$ is peak level of the housing price index, $h_{t}$ is the level of the housing price index in year $t$, and $z_{H}^{R}$ is the re-keyed value of the $\mathrm{z}$-score for the housing crisis component.

We followed this procedure to create three sets of 15 alternative measures of the GRI (labelled GRI-1 through GRI-15), one set each for the country-level, state-level, and metropolitan-level datasets. Each set was comprised of 12 fixed-peak versions (varying by peak year and duration) and three floating-peak versions (varying by duration). We then used principal components factor analysis to calculate one-factor solutions for each index. The alpha levels for each of the 45 indices are reported in Table 2. Alphas range from 0.553 to 0.886 for the country-level indices, from 0.647 to 0.880 for the state-level indices, and from 0.588 to 0.780 for metro-level indices. Alphas for the metro-level indices are somewhat weakened because state-level data on the financial sector must be substituted for metrolevel data, which are not available, causing some loss in precision. Among the fixed-peak variations, those using the peak year of 2007 tend to have the highest alphas; however, floating-peak variations tend to have higher alphas than the fixed-peak variations, which indicates that asynchronous variations more accurately capture the impact of the GR. Also, in general, indices of longer duration tend to have higher alphas than those of shorter duration, which suggests that a wider lens increases the reliability of the index.

In the Appendix, we provide further evidence about the relationships among the 15 versions of the GRI by showing their intercorrelations in the country, state, and metro datasets. In general, the intercorrelations among the 15 indices are relatively strong, but the correlations involving GRI-1 through GRI-3 (fixed-peak variations beginning in 2005) are the weakest, as we would suspect. Also, the intercorrelations are strongest in the metro 


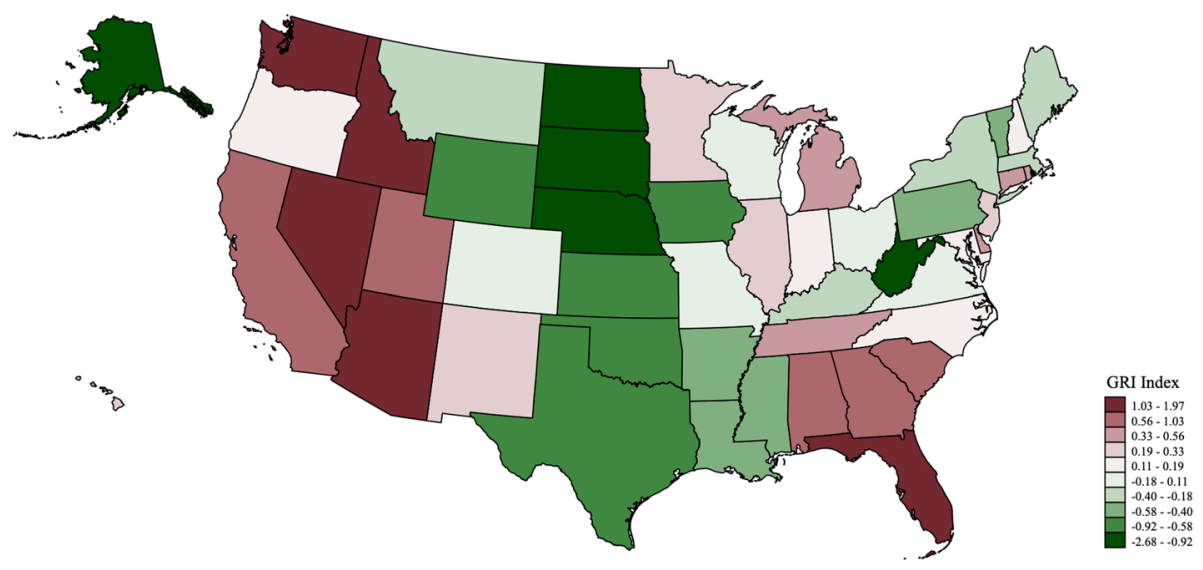

Fig. 2 State-level variation in the Great Recession Index (GRI-14)

dataset and weakest in the country dataset. We also see that intercorrelations involving the three floating-peak variations (GRI-13 through GRI-15) are among the strongest in each matrix, underscoring our sense that these three best capture the reality of the GR.

In the Online Supplement, we provide the calculated values of the 15 GRIs for the country, state, and metro datasets. We provide these as a resource for researchers interested in using them in their research. ${ }^{4}$

\section{A Research Application}

Previous research using earlier versions of the GRI demonstrated its utility at the national level for understanding perceived anti-immigrant prejudice (Kwak \& Wallace, 2018) and at the metro level for understanding the college earnings premium in metropolitan labor markets (Li et al., 2019). To further demonstrate the utility of the GRI for exploring sociological questions, we provide a research application here using the 50_States dataset analyzing the effects of the GRI on two measures of income inequality. We use GRI-14, the four-year floating-peak variant of the GRI, in our main analyses as we generally prefer the floatingpeak variations over the fixed-peak variations and the four-year period is the middle-most version of the floating-peak GRIs. However, in order to demonstrate the robustness of the measure, we replicate these analyses using the other 14 GRI measures.

In Fig. 2, we show the distribution of GRI-14 across the 50 U.S. states, which reflects the wide-ranging — and often overlooked—geographic variation in the Recession's impact within the United States. We see that the Recession hit hardest in Florida and several Western states (Washington, Idaho, Nevada, and Arizona) and was weakest in West Virginia and several Upper Plains states (North Dakota, South Dakota, and Nebraska).

\footnotetext{
${ }^{4}$ The GRI data is available on the open access platform OSFHOME via the link https://osf.io/269fy/? view_only $=4813977 \mathrm{a} 2 \mathrm{dda} 462 \mathrm{ca}$ bbb24bce0100317. Researchers can download the original data file and user manual for conducting their own analyses.
} 
In what follows, we first describe the state-level variables used in our analyses. Second, we discuss the specifications of the mixed effects model used to examine state-level variation in the effects of GRI on income inequality. Third, using two measures of income inequality - the Gini index and five income quintiles - we present results showing the temporal change in inequality, the effects of the GRI on inequality, and the heterogeneous temporal effects for different levels of the GRI on inequality for the years 2006 to 2017.

\subsection{Variable Descriptions}

The state-level data used in our analyses come from multiple public sources, including the American Community Survey, the Bureau of Economic Analysis, and the U.S. Census of Population. Variables in the analyses are mainly derived from 1-Year Estimates of the American Community Survey. The outcome variables measure income inequality using household income data. In the first analysis, we examine the effects of the GRI on the Gini index, the most commonly used measure of income inequality. The Gini ranges from 0 to 1 where 0 corresponds with equal shares of income being held by every household and 1 corresponds with all income being held by a single household. In the second analysis, we examine the effects of the GRI on five income quintiles which capture the share of household income owned by each fifth of households, ranging from poorest to richest. For the sake of this example, we classify these quintiles as follows: quintile $1=$ the poor; quintile $2=$ working class; quintile $3=$ middle class; quintile $4=$ upper middle class; and quintile $5=$ upper class

We include several covariates as control variables. Time is a counting variable scaled from 1 to 12 for each year of the analysis 2006 to 2017. Population size $(\ln )$ is the natural logarithm of the population of the state. Percent black and percent Hispanic are the percent of the labor force 16 years and over that is black and Hispanic, respectively. Percent female is the percent of the labor force 16 years and over that is female. Percent college-educated is the percent of the population 25 years and over with a bachelor's degree or higher. Percent unemployed is the percent of the labor force that is unemployed. Percent change in real hourly earnings is the annual change in the hourly earnings of production workers. Percent manufacturing and percent government represent the percent of employment in manufacturing and government, respectively. Lastly, union density is the percent of workers belonging to labor unions. Table 3 provides descriptive statistics for all variables used in our analyses.

\subsection{Analytical Strategy}

Our data are arrayed as a panel design comprised of 12 annual observations for the years 2006-2017 for 50 U.S. states, totaling 600 cases. We utilize two-level mixed effects models to examine the temporal change of income inequality over this period. Mixed effects models are useful in settings where repeated measurements are observed on the same unit of analysis over time (Singer \& Willett, 2003). Model specification involves four steps. First, we estimate the unconditional means model, which partitions total variation of income inequality into between- and within-state components. Second, we estimate the random coefficients model adding the time variable to assess the changes in income inequality across time. Third, we add the GRI and all control variables to assess the impact of the GRI net of covariates. Fourth, we include cross-level interaction terms between time and the GRI to 
Table 3 Descriptive statistics for state-level analysis, 2006-2017 ( $\mathrm{N}=600)$

\begin{tabular}{|c|c|c|c|c|}
\hline & Mean & S.D & Min & $\operatorname{Max}$ \\
\hline Gini index & 45.705 & 2.029 & 40.200 & 51.570 \\
\hline Share of income (1st Quintile) & 3.495 & .372 & 2.530 & 4.600 \\
\hline Share of income (2nd Quintile) & 9.018 & .590 & 7.490 & 10.600 \\
\hline Share of income (3rd Quintile) & 15.024 & .571 & 13.450 & 16.600 \\
\hline Share of income (4th Quintile) & 23.226 & .437 & 21.800 & 24.570 \\
\hline Share of income (5th Quintile) & 49.236 & 1.765 & 44.500 & 54.420 \\
\hline Great Recession Index (GRI14) & .000 & .840 & -2.684 & 1.966 \\
\hline Population size (ln) & 15.161 & 1.013 & 13.152 & 17.489 \\
\hline Percent black & 10.751 & 9.505 & .430 & 37.750 \\
\hline Percent Hispanic & 10.779 & 10.000 & .920 & 48.770 \\
\hline Percent females in the labor force & 46.932 & 1.252 & 42.157 & 49.893 \\
\hline Percent with college degrees & 28.413 & 5.082 & 15.900 & 43.400 \\
\hline Unemployment rate & 6.125 & 2.192 & 2.400 & 14.400 \\
\hline Percent change in real hourly earnings & .334 & 3.545 & -12.351 & 15.652 \\
\hline Percent manufacturing employment & 9.087 & 3.522 & 2.194 & 18.949 \\
\hline Percent government employment & 17.305 & 2.913 & 11.662 & 26.277 \\
\hline Union density (ln) & 10.596 & 5.362 & 1.600 & 25.300 \\
\hline
\end{tabular}

evaluate the heterogeneity of temporal changes in income inequality for different levels of GRI. The full-estimated model is represented by the equation:

$$
Y_{i t}=\beta_{0}+\beta_{1} T_{i t}+\beta_{2} G R I_{i}+\beta_{3} C_{i t}+\beta_{4} T_{i t} G R I_{i}+u_{0 i}+u_{1 i} T_{i t}+r_{i t}
$$

where $Y_{i t}$ is the predicted income inequality measure (either Gini or income quintiles) for state $\mathrm{i}$ at year $\mathrm{t} ; T_{i t}$ is time variable for state $\mathrm{i} ; G R I_{i}$ is the Great Recession Index for state $\mathrm{i} ; C_{i t}$ is a vector of control variables. $T_{i t} G R I_{i}$ is the interaction term between time and the GRI. $\beta \mathrm{s}$ are the fixed effects estimators. The random error has three components: $u_{0 i}$, the random effect of state $i$ on income inequality; $u_{1 i}$, the random effect of state $i$ on the effect of time on income inequality; and $r_{i t}$, the level-1 error.

The focus of this analysis is on the effects of three covariates. First, the time variable indicates the temporal change in income inequality over the 12-year period, net of other covariates. Second, the GRI variable indicates the one-time shock of the Great Recession on income inequality in a particular state. Third, the cross-level interaction term between time and the GRI expresses the aftershock, or more specifically, how the temporal change of income inequality varies by different levels of GRI. Alternatively, the GRI variable can be thought of as the short-term effect and the interaction term as the long-term heterogeneous effect of the GR.

\subsection{Results}

In Table 4, we present the results of mixed effects models predicting the Gini coefficient in 50 US states from 2006 to 2017. Model 1 shows the unconditional means model (or, alternatively, one-way ANOVA with random effects) to calculate the intraclass correlation coefficient (ICC). The ICC for income inequality is $0.833(3.426 / 0.686+3.426))$, meaning 


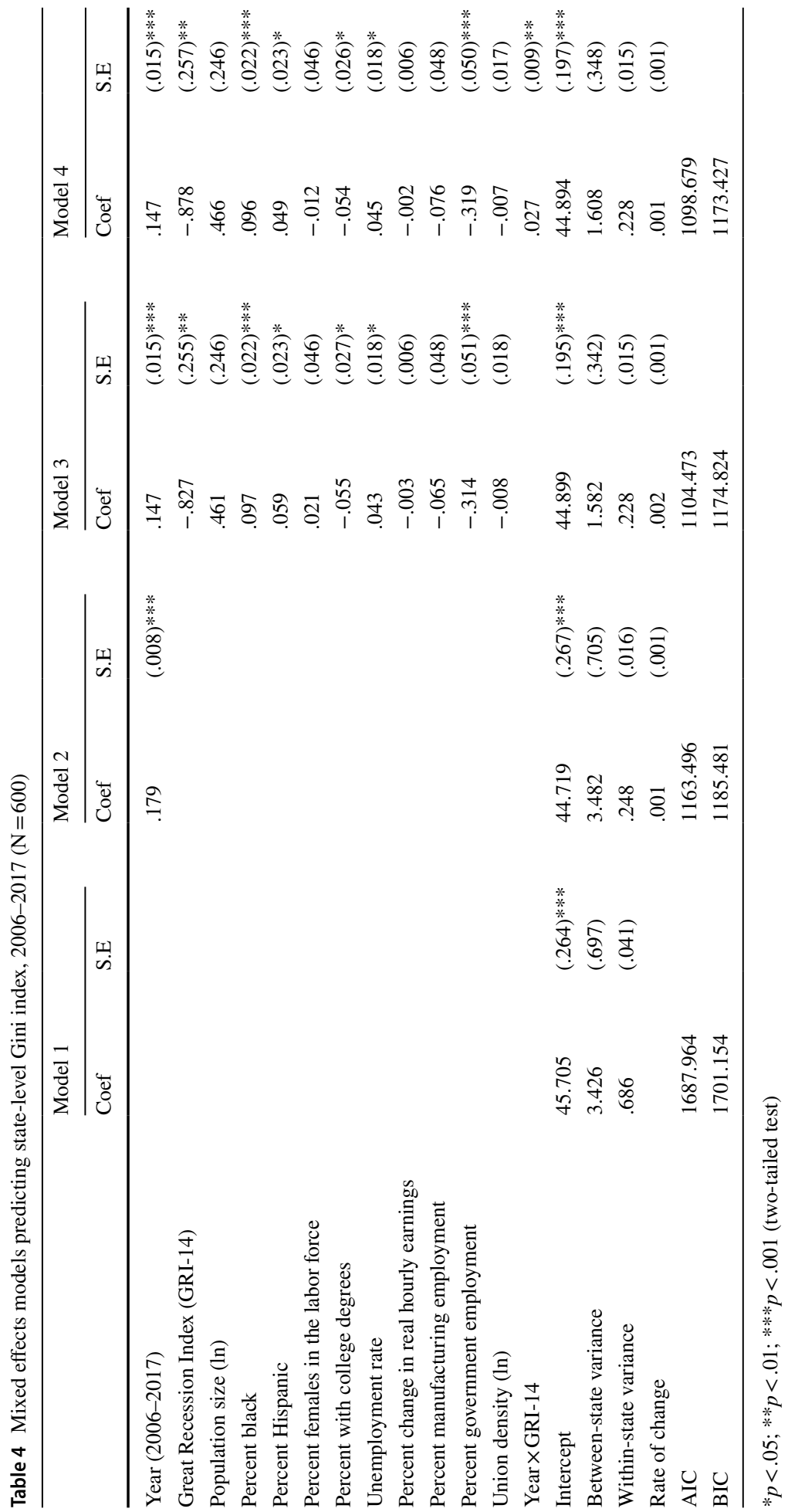




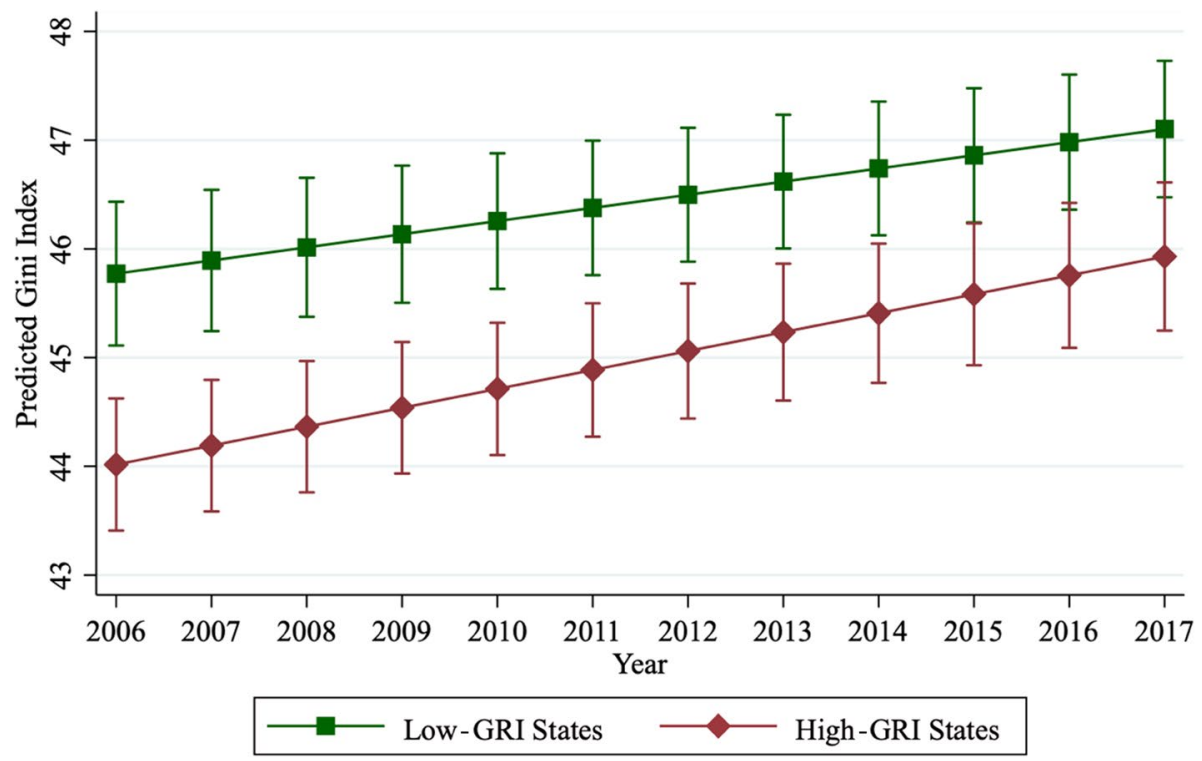

Adjusted Predictions with 95\% Confidence Intervals based on Model 4 reported in Table 2.

Fig. 3 Predicted Gini index in low- and high-GRI states in the U.S., 2006-2017

that $83.3 \%$ of the total variation in the Gini index can be explained by differences between states. In Model 2, we add the time variable to capture the annual change in Gini inequality. We find that levels of the Gini index increased significantly from 2006 to 2017. The estimated variance for the rate of change (shown at the bottom of model 2) is not significant, suggesting that levels of Gini inequality generally increased at similar rates across states.

Model 3 adds GRI-14 and the other covariates. The results show that the GRI-14 has a significant negative effect on the Gini net of other covariates. This result indicates that states where the Recession was more severe on average had lower levels of Gini inequality across years. The influences of other covariates meet our expectations. For example, higher proportions of black and Hispanic population were associated with significantly higher levels of the Gini index. Higher shares of college-educated persons are related to lower levels of Gini inequality. Higher unemployment leads to increased Gini inequality. Percent government employment is negatively related to Gini inequality. In addition, the estimated between-state variance in Model 3 is 1.582, compared to 3.426 in Model 1, a 53.8\% proportional reduction, suggesting that the added covariates significantly help to explain variation in the Gini index.

In Model 4, we add the cross-level interaction term between time and GRI-14 to examine how changes in the Gini vary by severity of the Recession. The cross-level interaction term is positive and significant, indicating that the Gini increased more in states where the Recession was more severe during this period. Coupled with the continuing negative significant effect of GRI-14, these results suggest that the Recession had the initial effect of reducing Gini inequality - most likely as high earners lost proportionately larger shares of their income-but then the aftershock of the Recession increased the Gini in each subsequent year-as high earners recouped their losses while income shares of lower earners diminished. The patterns of statistical significance of other covariates remain unchanged from Model 3. 
Figure 3 presents a graphic illustration of the heterogeneity of changes in Gini inequality by levels of GRI-14 derived from the analysis in Model 4 of Table 4. Two plot lines depict predicted values of Gini inequality over the 12-year period: high-GRI states (those at one standard deviation above the mean GRI) and low-GRI states (those at one standard deviation below the mean GRI), holding all other covariates at their means. The results show that, net of other covariates, high-GRI states tended to have lower levels of Gini inequality, but their levels of inequality increased more dramatically over time compared to low-GRI states.

The results in Table 4 indicate the factors affecting state-level variation in the Gini, an overall measure of income inequality, but do not address precisely how the GRI impacted the income distribution. To address this second question, in Table 5 we replicate the full model with cross-level interactions for income quintiles. The results reinforce and explicate the results we found for the Gini. First, with respect to the time trend variable, we see that income shares of the first through fourth quintiles decreased over time, whereas only the income share of the richest quintile increased with time. Second, GRI-14 had a positive and significant effect on income shares of the first through third quintiles, no significant impact on the fourth quintile, and a significant negative effect on the fifth quintile. This reinforces the results for the Gini by showing that initial income losses from the Recession were greatest for the top quintile; lower quintiles improved their income shares not because they gained income but because their losses were not as large, relative to the rich. Third, the interaction terms between time and GRI-14 had negative and significant effects for income shares of the first through third quintiles, no significant effects for the fourth quintile, and positive and significant effects for the fifth quintile. This further reinforces results from the Gini analysis by showing that income shares of the top earners increased in the aftermath of the Recession, while income shares of the bottom three quintiles declined.

Combining these findings, we offer the following sociological interpretation of the effects of the Great Recession on income inequality:

(1) The initial shock of the Great Recession increased the income shares of poor, workingclass, and middle-class households, but the aftershocks of the Recession eroded the income shares of these three groups. All the while, income shares of poor, workingclass, and middle-class households decreased as a function of time.

(2) The initial shock of the Great Recession had no net effect on the income share of uppermiddle-class households, and the aftershock of the Recession also had no net effect on the income share of this group. However, the income share of the upper middle class decreased as a function of time.

(3) The initial shock of the Great Recession decreased the income share of upper-class households, but the aftershock of the Recession increased their income share. Also, the income share of the upper class continued to increase as a function of time.

Overall, these results suggest a key process that ratchets up inequality in the aftermath of severe economic downturns: the rich take a large initial hit but tend to recover quickly, while lower income groups take milder hits, but recover more sluggishly. The result is that overall inequality is greater than before the downturn began (Picketty \& Saez, 2015; Wright \& Rogers, 2015; Hyde et al., 2018).

Figure 4 provides a graphic presentation of the results from Table 5 by showing the predicted income shares of the first (Panel A) and fifth (Panel B) quintiles with respect to the severity of the Great Recession over time. In each panel, the two plot lines 


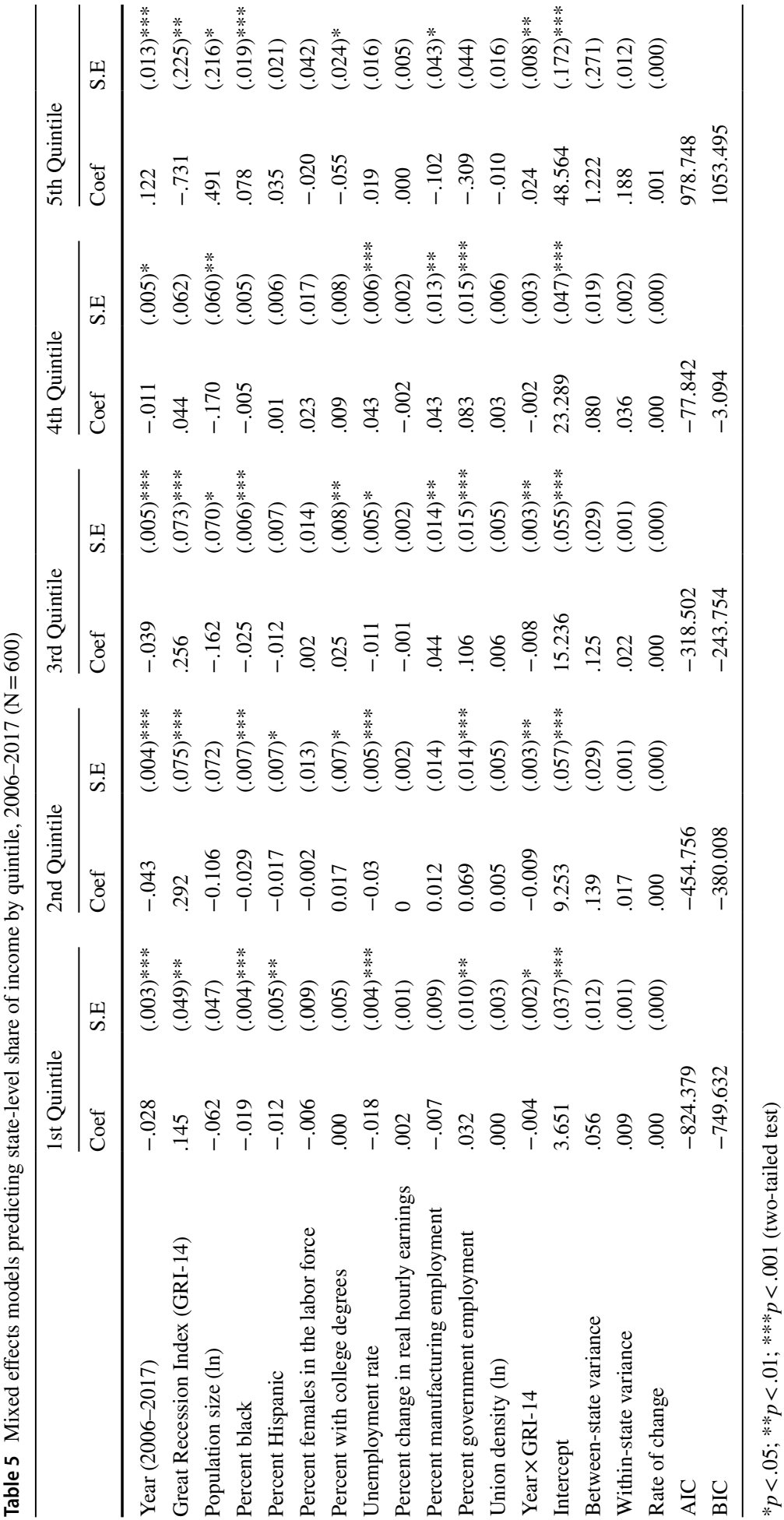


Panel A: Predicted Share for 1st Quintile

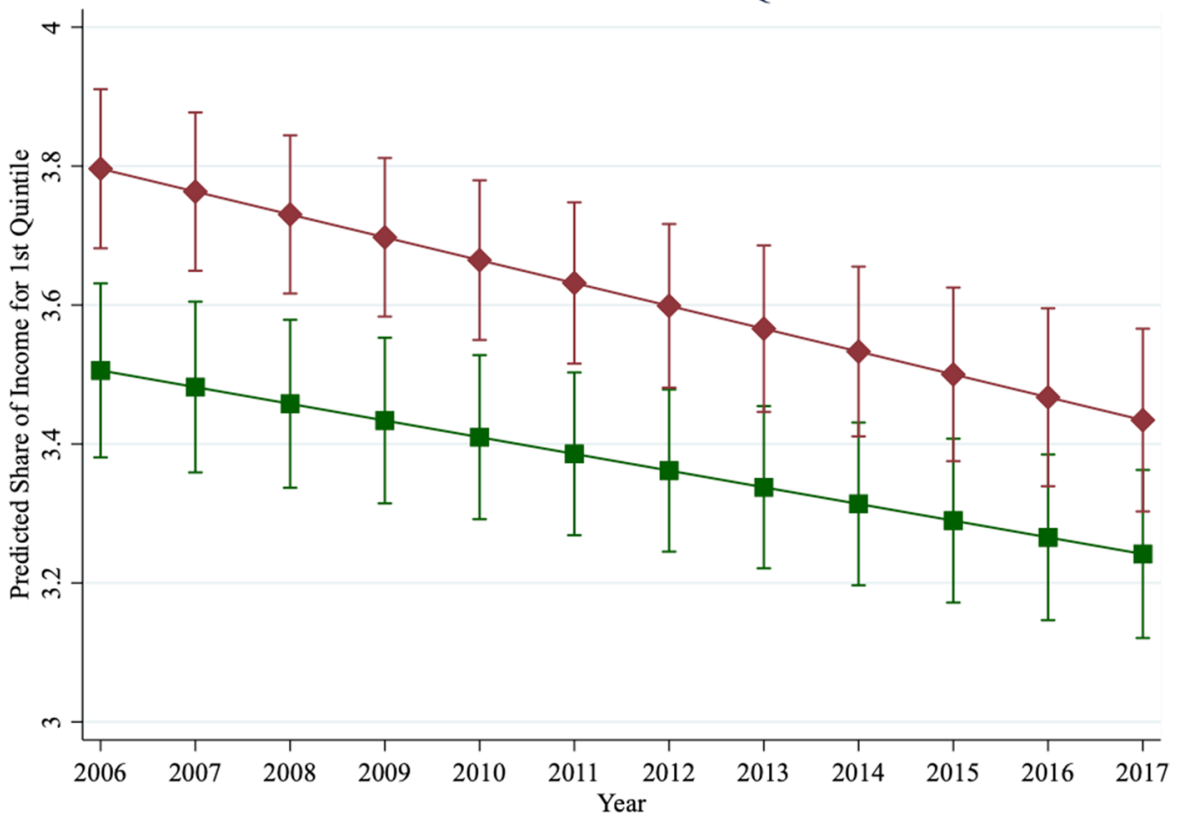

Panel B: Predicted Share for 5th Quintile

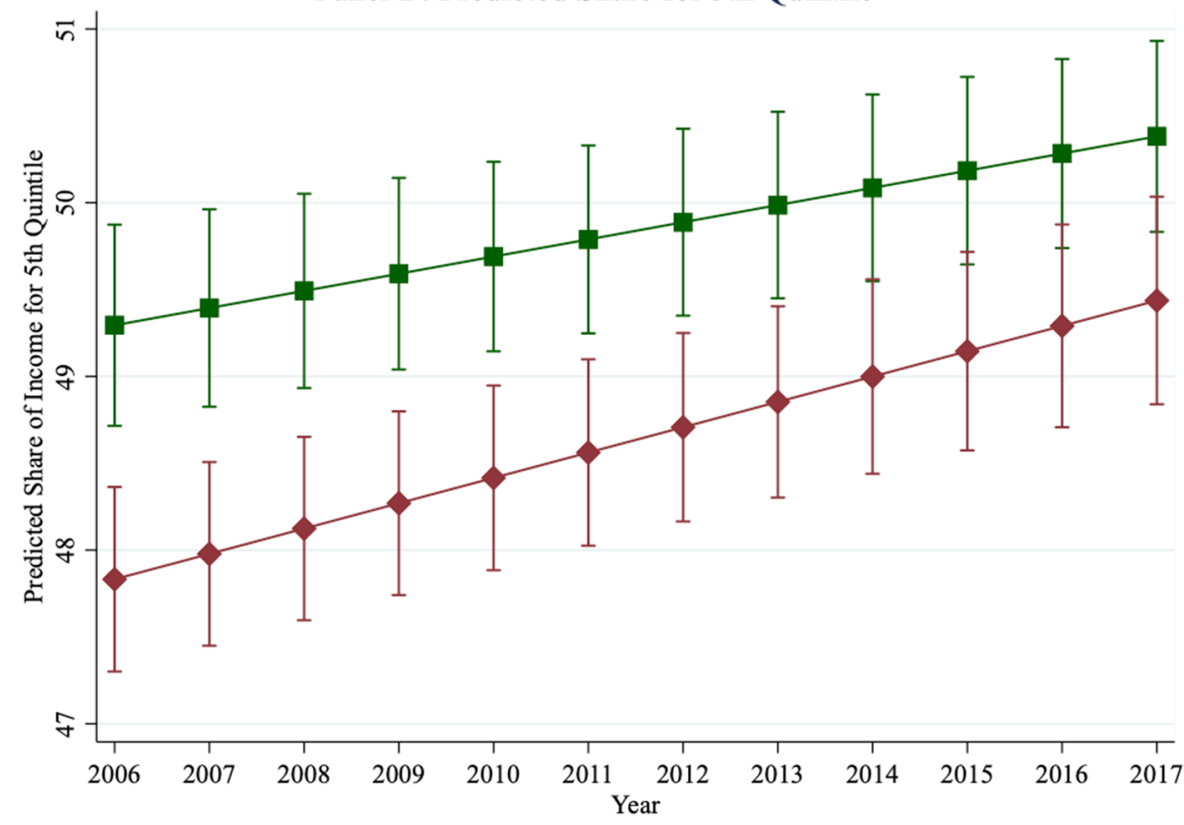

Adjusted Predictions with 95\% Confidence Intervals based on results reported in Table 3.

Fig. 4 Predicted quintile share of income in low- and high-GRI states in the U.S., 2005-2017 
Table 6 Mixed effects models predicting state-level Gini index using 15 alternative measures of the Great Recession index, 2006-2017 $(\mathrm{N}=600)$

\begin{tabular}{|c|c|c|c|c|c|c|}
\hline & \multicolumn{2}{|c|}{ Year (2006-2017) } & \multicolumn{2}{|l|}{ GRI } & \multicolumn{2}{|c|}{ Year $\times$ GRI } \\
\hline & Coef & S.E & Coef & S.E & Coef & S.E \\
\hline GRI-1 & .158 & $(.015)^{* * *}$ & -.248 & $(.372)$ & .018 & $(.011)$ \\
\hline GRI-2 & .157 & $(.015)^{* * *}$ & -.756 & $(.348)^{*}$ & .027 & $(.010)^{*}$ \\
\hline GRI-3 & .156 & $(.015)^{* * *}$ & -.820 & $(.338)^{*}$ & .028 & $(.010)^{* *}$ \\
\hline GRI-4 & .151 & $(.015)^{* * *}$ & -1.012 & $(.293)^{* *}$ & .031 & $(.010)^{* *}$ \\
\hline GRI-5 & .150 & $(.015)^{* * *}$ & -1.028 & $(.277)^{* * *}$ & .030 & $(.010)^{* *}$ \\
\hline GRI-6 & .149 & $(.015)^{* * *}$ & -1.005 & $(.270)^{* * *}$ & .030 & $(.009)^{* * *}$ \\
\hline GRI-7 & .147 & $(.015)^{* * *}$ & -1.030 & $(.260)^{* * *}$ & .025 & $(.010)^{* *}$ \\
\hline GRI-8 & .147 & $(.015)^{* * *}$ & -.990 & $(.256)^{* * *}$ & .025 & $(.009)^{* *}$ \\
\hline GRI-9 & .148 & $(.015)^{* * *}$ & -.969 & $(.254) * * *$ & .027 & $(.009)^{* *}$ \\
\hline GRI-10 & .149 & $(.015)^{* * *}$ & -1.034 & $(.292)^{* * *}$ & .019 & $(.011)$ \\
\hline GRI-11 & .149 & $(.015)^{* * *}$ & -1.052 & $(.284)^{* * *}$ & .024 & $(.011)^{*}$ \\
\hline GRI-12 & .150 & $(.015)^{* * *}$ & -1.039 & $(.282)^{* * *}$ & .027 & $(.011)^{*}$ \\
\hline GRI-13 & .147 & $(.015)^{* * *}$ & -.865 & $(.267)^{* *}$ & .027 & $(.009)^{* *}$ \\
\hline GRI-14 & .147 & $(.015)^{* * *}$ & -.878 & $(.257)^{* *}$ & .027 & $(.009)^{* * *}$ \\
\hline GRI-15 & .148 & $(.015)^{* * *}$ & -.875 & $(.253)^{* *}$ & .027 & $(.009)^{* *}$ \\
\hline
\end{tabular}

All models include controls for population size (ln), percent black, percent Hispanic, percent females in the labor force, percent with college degrees, unemployment rate, percent change in real hourly earnings, percent manufacturing employment, percent government employment, and union density (ln)

$* p<.05 ; * * p<.01 ; * * * p<.001$ (two-tailed test)

represent predicted income shares over the 12-year period: high-GRI states (one standard deviation above the mean GRI) and low-GRI states (one standard deviation below the mean GRI), holding all other covariates at their means. In Panel A for the poorest quintile, we see that income shares in both high- and low-GRI states decline over time; however, income shares are generally higher and decline at a faster rate in high-GRI states than low-GRI states. In Panel B for the richest quintile, we see that income shares in both high- and low-GRI states increase over time; however, income shares are generally lower, and they increase at a faster rate in high-GRI states than low-GRI states. Overall, these results suggest that income inequality increased the most in states that were hardest hit by the Recession by causing more rapid declines in the income share of the lowest quintile and more rapid increases in the income share of the highest quintile.

In our final analysis, we test the robustness of effects of the GRI. Replicating the analysis in Model 4 of Table 4, we estimate 15 models substituting each of the 15 variations of the GRI to determine their effects on the Gini index. (The values shown for GRI-14 replicate those for GRI-14 from Table 4.) Table 6 shows the results of this analysis. To save space, we show only the effects of the time variable, the GRI, and the interaction term between time and the GRI for each of the 15 models.

The results show remarkable consistency across the 15 models. First, the time coefficient is consistently positive and significant for all 15 models. Time's effect is stronger for the three fixed-peak variations that start in 2006 (GRI-1 through GRI-3), but differences in the magnitude of the time coefficient are negligible. The effect of the GRI is negative and significant for all variations of the GRI except GRI-1, although the 
magnitude of the coefficient is highly variable across specifications. Finally, the interaction term between time and GRI is positive and significant for all variations except GRI-1 and GRI-10. It is worth noting that these two variations had the two lowest Cronbach's alphas (see Table 2). These two variations began in the least defensible peak years (2006 and 2009) for fixed-peak variations and had the shortest duration (three years), which militate against reliable results. Also, for each threesome of fixed-peak variations of the GRI that start in the same peak year (GRI-1 through GRI-12), there is modest variation in the coefficients of the GRI and the interaction term for time and the GRI, based on the duration of the index. By comparison, for the floating-peak variations (GRI-13 through GRI-15), there is much more consistency in these coefficients. In other words, results for the three floating-peak (i.e., asynchronous) variations of the GRI are virtually interchangeable regardless of the duration specified.

\section{Discussion and Conclusions}

In this paper, we have outlined a procedure for calculating the Great Recession Index, developed 15 alternative measures each for countries, U.S. states, and U.S. metropolitan areas, and provided a research application to demonstrate its utility for addressing sociological questions such as how the GR affected income inequality in the 50 U.S. States. In the Online Supplement, we have provided values for the 45 different GRIs for researchers to employ in their own research. We have shown that the GRI overcomes several limitations of previous research and extends the possibilities of GR research in several new directions.

First, consistent with many theoretical accounts of the GR (Fligstein \& Goldstein, 2011; Seefeldt et al., 2013), we construct the GRI as a multidimensional construct comprised of four interrelated economic crises-economic decline, employment loss, the housing crash, and the financial crisis. The measure thus nimbly accounts for the varying timing, duration, and severity of these different strands of the Recession. Second, the GRI addresses the scarcity of rigorous, macro-level empirical studies on the GR by providing a measure that is suitable for large, geospatial units like countries, states, and metropolitan areas. In this way, it complements and extends the abundance of extant research on micro-level outcomes of the Recession. Third, the GRI taps into the considerable geospatial variation in the severity of the GR, which permits more realism and precision in assessing the Recession's effects. Fourth, the GRI is especially well-suited for unlocking the long-term impact of the GR on social outcomes, overcoming the short-term bias of most GR research. Indeed, when employed with appropriate statistical techniques, the GRI permits researchers to cleanly distinguish between the initial shock of the Recession, its aftershock, and the ongoing effects of time, as we demonstrated in our research application explaining household income inequality.

The GRI is adaptable to a variety of different research designs where macro-level data are appropriate. For example, using a simple, cross-sectional design of affluent democratic countries, it would be suitable for analyzing the effects of the GR on the percentage of persons living in relative poverty where the dependent variable might be measured up to a decade after the end of the Recession. Or, in a similar vein, one could address the same question perhaps more rigorously by using a two-panel design (Markus, 1979) in which the dependent variable is measured 10 years apart, at time $t$ (about the time of the GR) and time $t+10$ (about 10 years later). Alternatively, using a national sample of the U.S. 
population, one could geocode state-level GRI scores to respondents' state of residence and utilize hierarchical linear models (Raudenbush \& Bryk, 1992) to examine the impact of the GR as a Level-2 variable on citizens' trust in government as a Level-1 variable. One could further examine effects of cross-level interactions between the GRI and demographic features of citizens to identify the differential impact of the Recession on citizens' attitudes by age, education, race/ethnicity, gender, or social class. Finally, one could employ metrolevel GRI scores using a variety of longitudinal designs including conventional time series (Ostrom, 1990), interrupted time series (McDowall et al., 1980), or pooled time series analysis (Sayrs, 1989) to examine the impact of the GR on percentages of the metro-area population with no health insurance coverage. Or, perhaps more optimally, one could utilize mixed effects models (Singer \& Willett, 2003), such as we employed in our research application with income inequality to examine the longitudinal impact of the GR. All of these designs lend themselves to the investigation of relevant interaction effects between the GRI and time or other covariates to further specify the nuances of the Recession's impact.

We further note that the basic procedures outlined here could be extrapolated to study the effects across time and space of a variety of catastrophic events such as wars, civil unrest, climate change, natural disasters, or pestilence, so long as reliable quantitative indicators of the relevant dimensions of these events are available or can be derived. All the criteria discussed above - dimensionality, timing, duration, severity, and synchronicitywould be equally relevant in the construction of such indices. Moreover, some applications might lend themselves to a more textured analysis than ours if indicators are available on a more localized and/or time-sensitive basis. One urgent application of this procedure that comes quickly to mind would be an examination of the economic and/or political impact of the COVID-19 pandemic. How did the severity of the COVID pandemic in different U.S. counties affect the mental health of citizens or their propensity to vote Democratic or Republican in the 2020 presidential election? A variety of indicators of the pandemic are already readily available including incidence of cases, number of COVID tests performed, number of tests that are positive, hospitalization rates, number of ICU cases, and deaths. Such data are available on a daily, or seven-day average basis, allowing more precision in measuring the severity of the crisis at different points in time. ${ }^{5}$ Such data are also available in a more localized basis including at the level of U.S. counties, which permits a much more fine-grained geospatial design that incorporates the diversity or urban and rural settings in the U.S. We hope that researchers will find our general methodology useful in their own research, whether it involves investigation of the effects of the GR or any manner of catastrophic events that warrant scholarly investigation.

\section{Appendix}

See Table 7

\footnotetext{
${ }^{5}$ Note that the use of daily or seven-day average data for COVID-19 indicators need not require that the rest of the analysis be conducted at this level. Once constructed, the COVID-19 Index could be used to analyze outcomes using monthly, quarterly or annual data.
} 


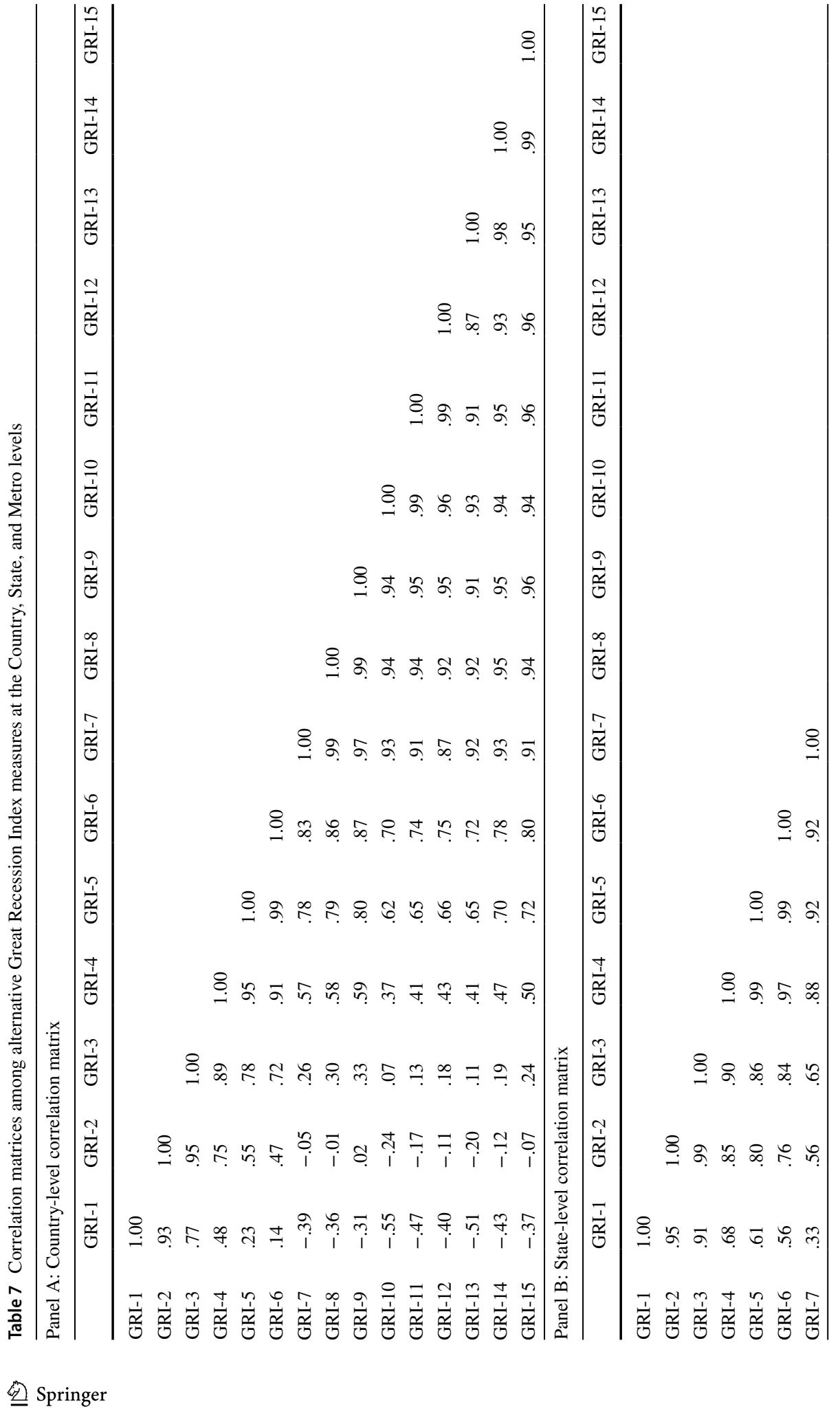




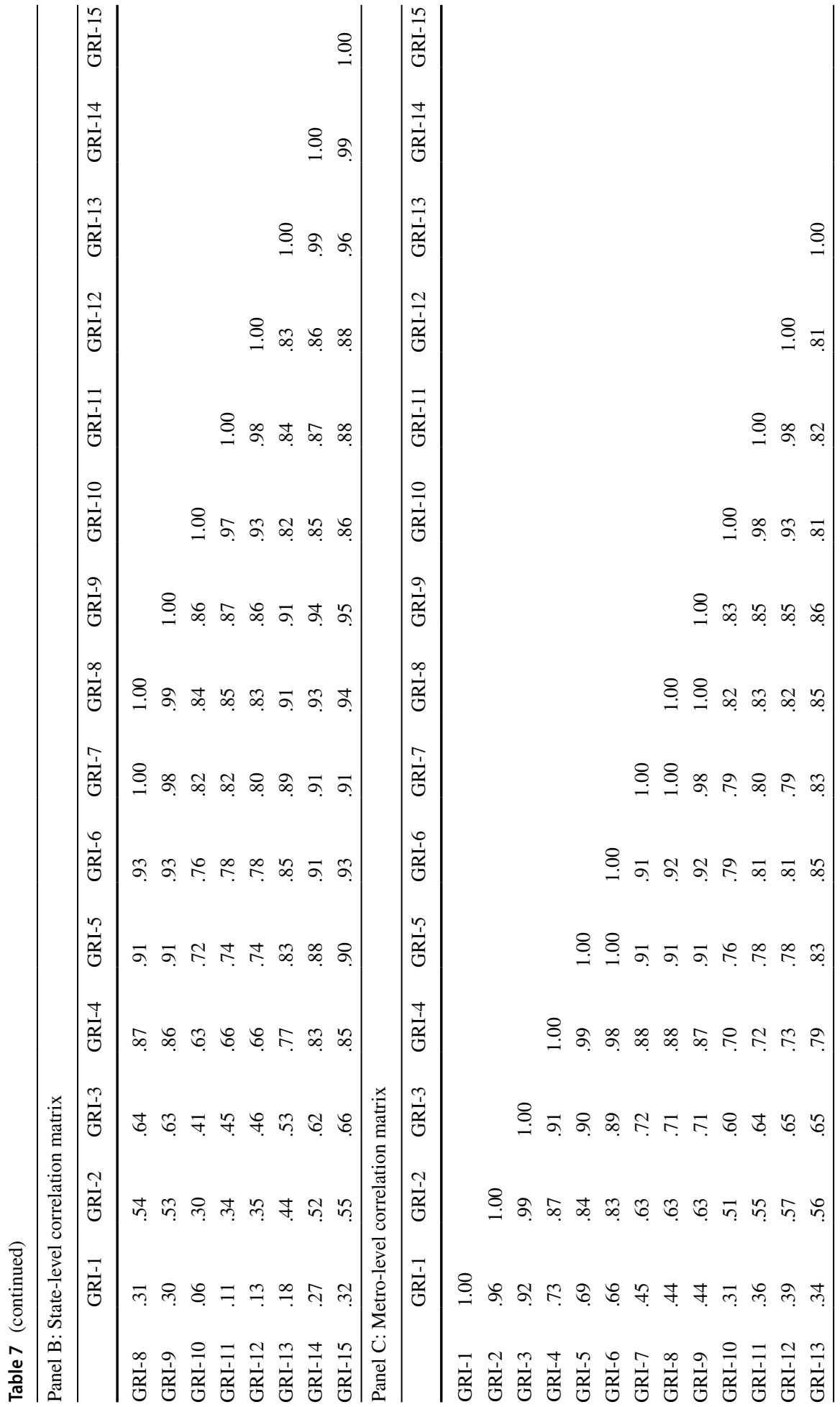




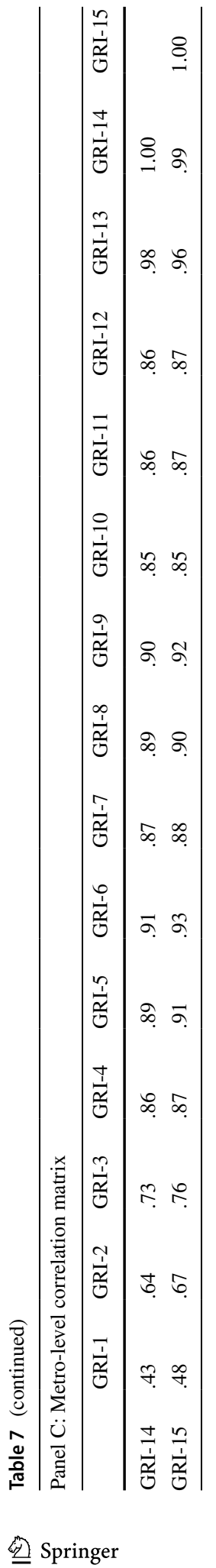




\section{References}

Brooks, C., \& Manza, J. (2013). A broken public? Americans' responses to the Great Recession. American Sociological Review, 78(5), 727-748.

Burgard, S. A., \& Kalousova, L. (2015). Effects of the Great Recession: health and well-being. Annual Review of Sociology, 41, 181-201.

Butrica, B., Smith, K. E., \& Toder, E. J. (2010). What the 2008 stock market crash means for retirement security. Journal of Aging Social Policy, 22(4), 339-359.

Cagney, K. A., Browning, C. R., Iveniuk, J., \& English, N. (2014). The onset of depression during the Great Recession: Foreclosure and older adult mental health. American Journal of Public Health, 104(3), 498-505.

Daly, M. C., \& Marks, E. M. (2014). The labor market in the aftermath of the Great Recession. Business Economics, 49(3), 149-155.

Danziger, S. (2013). The effects of the Great Recession. Annals of the American Academy of Political and Social Science, 650, 6-24.

Fligstein, N., \& Goldstein, A. (2011). The roots of the Great Recession. In D. B. Grusky, B. Western, \& C. Wimer (Eds.), The Great Recession (pp. 21-55). Russell Sage Foundation.

Fogg, N. P., \& Harrington, P. E. (2011). Rising mal-employment and the Great Recession: The growing disconnection between recent college graduates and the college labor market. Continuing Higher Education, 75, 51-65.

FRED (Federal Reserve Economic Data). (2020). Economic research. Retrieved from <https://fred.stlou isfed.org $\geq$.

Gillespie, M. D. (2014). The family as an economic institution: Historical contingencies and the Great Recession. International Journal of Sociology of the Family, 40(1), 1-26.

Grusky, D. B., Western, B., \& Wimer, C. (2011). The Great Recession. Russell Sage Foundation.

Havins, N. (2014). Technology industries helped post-Great Recession jobs grow faster in northern than in southern California. Monthly Labor Review, 137, 1-9.

Houle, J. N., \& Light, M. T. (2014). The home foreclosure crisis and rising suicide rates, 2005 to 2010. American Journal of Public Health, 104(6), 1073-1079.

Hyde, A., Wallace, M., \& Vachon, T. (2018). Neoliberalism, financialization, and income inequality in 18 affluent democracies, 1981-2011". Social Currents, 5, 193-211.

Johnson, K. M., Curtis, K. J., \& Egan-Robertson, D. (2017). Frozen in place: Net migration in sub-national areas of the United States in the era of the Great Recession. Population and Development Review, 43(4), 599-623.

Kahler, M., \& Lake, D. A. (2013). Politics in the new hard times: The Great Recession in comparative perspective. Cornell University Press.

Kalleberg, A. L., \& von Wachter, T. (2017). The U.S. labor market during and after the Great Recession. Russell Sage Foundation Journal of the Social Sciences, 3, 1-19.

Kwak, J., \& Wallace, M. (2018). The impact of the Great Recession on perceived immigrant threat: A crossnational study of 22 countries. Societies, 8(3), 52. https://doi.org/10.3390/soc8030052

Li, A., Wallace, M., \& Hyde, A. (2019). Degrees of inequality: The Great Recession and the college earnings premium in U.S. metropolitan areas. Social Science Research. https://doi.org/10.1016/j.ssres earch.2019.102342

Markus, G. B. (1979). Analyzing panel data. Sage.

McCorkell, L., \& Hinkley, S. (2019). The post-recession labor market: An incomplete recovery. Institute for research on labor and employment. https://irle.berkeley.edu/the-post-recession-labor-market-an-incom plete-recovery/.

McDowall, D., McCleary, R., Meidinger, E., \& Hay, R. A., Jr. (1980). Interrupted time series analysis. Sage.

Mishel, L., Bivens, J., Gould, E., \& Shierholz, H. (2012). The state of working America (12th ed.). Cornell University Press.

Margalit, Y. M. (2013). Explaining social policy preferences: Evidence from the Great Recession. The American Political Science Review, 107(1), 80-103.

Moffitt, R. A. (2013). The Great Recession and the social safety net. Annals of the American Academy of Political and Social Science, 650, 143-166.

National Bureau of Economic Research. (2021). Business cycle dating. <https://www.nber.org/research/ business-cycle-dating $>$.

O'Connor, K. J. (2017). Who suffered most from the Great Recession? Happiness in the United States. The Russell Sage Foundation Journal of the Social Sciences, 3(3), 72-99.

Ostrom, C. W. (1990). Time series analysis: Regression techniques. Sage.

Peck, D. (2010). How a new jobless era with transform America. The Atlantic, 305, 42-56. 
Piketty, T., \& Saez, E. (2015). Top incomes and the Great Recession: Recent evolutions and policy implications. IMF Economic Review, 61, 456-478.

Pontell, H. N., \& Geis, G. (2014). The trajectory of white-collar crime following the great economic meltdown. Journal of Contemporary Criminal Justice, 30(1), 70-82.

Raudenbush, S., \& Bryk, A. S. (1992). Hierarchical linear models: Applications and data analysis methods. Sage.

Reardon, C. (2009). Economic squeeze-the recession's impact on behavioral health. Social Work Today, $9(2), 12$.

Rosenfeld, R. (2014). Crime and the Great Recession: Special issue. Journal of Contemporary Criminal Justice, 30(1), 4-6.

Rouse, S. M., \& Ross, A. D. (2018). Children of the Great Recession: Millennials and the economy. In S. M. Rouse \& A. D. Ross (Eds.), The politics of millennials: Political beliefs and policy preferences of America's most diverse generation (pp. 47-76). University of Michigan Press.

Sayrs, L. W. (1989). Pooled time series analysis. Sage.

Schneider, D. (2015). The Great Recession, fertility, and uncertainty: Evidence from the United States. Journal of Marriage and Family, 77(5), 1144-1156.

Schneider, D., Harknett, K., \& McLanahan, S. (2016). Intimate partner violence in the Great Recession. Demography, 53(2), 471-505.

Schanzenbach, D. W., Nunn, R., Bauer, L., Boddy, D., \& Nantz, G. (2016). Nine facts about the Great Recession and tools for fighting the next downturn. The Brookings Institution.

Schuyler, S. (2015). Reality television, melodrama, and the Great Recession. Studies in Popular Culture, $37(2), 43-65$.

Seefeldt, K., Graham, J., Abner, G., Bolinger, J., Xu, L., \& Smiley, T. (2013). The Great Recession: Definition, duration, and impact. In K. Seefeldt \& J. D. Graham (Eds.), America's poor and the Great Recession (pp. 5-16). Indiana University Press.

Seefeldt, K., \& Graham, J. D. (2013). America's poor and the Great Recession. Indiana University Press.

Sherman, J. (2013). Surviving the Great Recession: Growing need and the stigmatized safety net. Social Problems, 60(4), 409-432.

Singer, J. D., \& Willett, J. B. (2003). Applied longitudinal data analysis: Modeling change and event occurrence. Oxford University Press.

Tcherneva, P. R. (2012). The role of fiscal policy: Lessons from stabilization efforts in the United States during the Great Recession. International Journal of Political Economy, 41(2), 5-26.

Villarreal, A. (2014). Explaining the decline in Mexico-U.S. Migration: The effect of the Great Recession. Demography, 51(6), 2203-2228.

Wright, E. O., \& Rogers, J. (2015). American society. (2nd ed.). W. W. Norton \& Company.

Publisher's Note Springer Nature remains neutral with regard to jurisdictional claims in published maps and institutional affiliations. 